\title{
Meeting the Skills Gap with a Focus on ERP Education at SUNY; Farmingdale State College and Binghamton University
}

\author{
Jill Anne 0'Sullivan1, Dennis Goldensohn'2, Rachel Hinton ${ }^{3}$ \\ ${ }^{1}$ School of Business, Farmingdale State College, Farmingdale, USA \\ ${ }^{2}$ Arkwin Industries, Westbury, USA \\ ${ }^{3}$ Watson School of Engineering, Binghamton University, Binghamton, USA \\ Email: osullija@farmingdale.edu
}

Received 25 August 2014; revised 25 September 2014; accepted 17 October 2014

Academic Editor: Grigorios L. Kyriakopoulos, National Technical University of Athens (NTUA), Greece

Copyright (C) 2014 by authors and Scientific Research Publishing Inc.

This work is licensed under the Creative Commons Attribution International License (CC BY).

http://creativecommons.org/licenses/by/4.0/

(c) (i) Dpen Access

\section{Abstract}

Serious considerations today abound about students in college nowadays who need to be better prepared for entry into the workforce upon graduation. Collaboration between private, public and academic organizations are generating new requirements and demands that must be addressed for workforce efficiencies. This paper provides a testimony to the success of this program [1]. The universities-industries-and-associations support in the conception, design and implementation of innovations is making for better preparation in the classroom. This grassroots type of effort to bring real world tools into the classroom should be supported entirely. If industry needs this type of prepared student, this type of collaboration results will be mutually beneficial. The purpose of this paper is to contribute to the body of knowledge in support of the creation and development of relationships among different societal sectors. We have brought together researchers, professionals, practitioners and decision-makers from the Academic, Private and Public Sectors to share our findings, experience and knowledge in regards to the applications and impact of information and communication with technology tools. This paper brings together what has transpired with Farmingdale State Colleges ERP class, ERP Alliance collaboration with Synergy Resources, INFOR Global Solution, Binghamton University, Arkwin Industries and APICS NYC/LI [1]. Regarding Enterprise computing, we believe that collaboration is essential for successful use of this tool. Having industry provide access to the ERP tool, instruction on how to present and teach with the tool as well as the need for students prepared with this skill set is closest to the requirement than any other type of theory or concept offering [2]. Together this can make for better preparation at a time when college graduates are struggling to distinguish themselves and their skills upon graduation. Companies are hiring and paying more for this skill today. Students from Farmingdale State 
College and Binghamton University are having the opportunity to use one of the most prevalent ERP tools available today based on the collaborations and developed relationships with industry leaders. Together we are creating class corroborations with this tool to better prepare students with this virtual collaboration. Never before has it been more important to prepare college students for immediate usefulness to industry upon hiring than it is today. SUNY recognizes this fact [3]. Many academic entities are attempting to align their strategic plan with the power of closely recognizing what is needed by industry for prepared adept ERP students.

\section{Keywords}

\section{ERP Education}

\section{Introduction}

The use of this tool at Farmingdale State College has proven very effective in preparing students for industry positions. The proven success of this program and these students has been across industries that need enterprise application comprehension in the skills of new employees. These students acquired ERP knowledge and skills sets that put them ahead of competition with new employees. The hands-on apprenticeship type training in this classroom establishes preparation that is as good as or better than industry training that is in demand. There is the demand pull and pushing the technology through college courses like this has enabled better preparation of new employees for corporations benefit. Combining instruction techniques and this tool with Binghamton University is an effort towards helping students acquire this skill set.

Using real world tools, specifically ERP, in academia is a reality today, with university and industry collaborations allowing for a hands-on experience in the classroom that replicates industry applications. This synergistic relationship provides opportunities for students to acquire knowledge using this real tool that imitates what is used in industry. Schools supported by several ERP vendor initiatives, are increasingly integrating enterprise systems in their curricula [2].

Today college students need to be prepared with the knowledge of enterprise resource planning (ERP) software in order to be of immediate maximum usefulness to industry employers. Research indicates the need for a shift to experiential learning in the classroom and provides evidence for its effectiveness and benefits over traditional models of passive learning (Ellis \& Letourneau, 2001; Gold, 2002; Hakeem, 2001). Kolb (1984) defines experiential learning as "process whereby knowledge is created through the transformation of experience". Just as important is the effective ERP training in corporations of those employees new to ERP. Validating academic training by reviewing what is done in academia as compared to how companies train and educate employees that are new to ERP has been produced which reflects the importance of this effort [1].

\section{Industry Issues, Demand Pull}

There is a problem with new hires not meeting the needs of companies regarding their ERP education and skills. There is a problem with students not being prepared enough in ERP to be considered for ERP positions resulting in a demand for this type of ERP new employee.

Research has shown that supervisors, in busy times, are often in a conflict between spending time with new employees and spending time on their operational responsibilities. Supervisors are often not the best trainers. Often, there are not enough ERP trainers in a department to ensure proper ERP understanding of new employees. Most managers are not trained or experienced in working successfully with people from vastly different cultures. In the absence of skills, managers are likely to create friction and lose productivity. When candidates are in short supply, mandatory skills and experience of applicants are often softened to a point that new recruits negatively affect the overall productivity of the company. The difference between top performers, average and low performers in skilled jobs is huge [1].

\section{An Industry Ally Perspective}

According to Dennis Goldensohn, who works at Arkwin Industries, and uses the featured ERP systems as well 
as being an Alumni of Farmingdale State College believes that learning and understanding a system can be taught by utilizing the actual system that is being used in local, national and international companies like his. Hands-on learning experiences are the most satisfying and thorough way to learn. The apprenticeship nature of this type of learning needs to be reconsidered in the workforce. When a student is presented with a topic such as Enterprise Resource Planning Systems-ERP, this can be quite overwhelming and confusing. To mitigate this, we need to have a working model available to help the student navigate the theory learned in the classroom.

ERP systems are very complex and they are the system of choice for companies who want to encompass all of operations within and outside of the organization. Thus the organization is part of the larger system, the "Supply Chain". Companies are no longer one to themselves, thus they require to be integrated with all of their internal as well as their external customers and suppliers.

Before ERP systems were the standard, companies utilized MRP II systems and other disparate systems that were not linked seamlessly. Thus the signals sent throughout the organization and the external supply chain was not synchronized and signals sent were not timely. To this point, an ERP system encompasses all of the tactical groups within the organization and all of the external and internal suppliers-customers in a synchronized scenario. This then creates order and better decisions can be made on data that is timely and accurate.

So how can students have this at their figure tips when learning about ERP systems? The best way is to have a system that is used in a laboratory setting that is exactly the same as the ones utilized in business. Having a system available, enables the instructor to create real time models-mock-ups of what actually occurs in a modern business and thus challenges the student to take the theory and apply it. In Lean the fourth rule states; "Experiment at the lowest level towards the Ideal State". Then reflect on the outcomes and then experiment again. This cannot be done via a textbook. This can only be done utilizing the technology-system that the textbook is relating to.

Once a student has the ability to navigate an ERP system successfully, the difference between ERP system software providers is what the screen looks like and what key stroke need to be clicked. The general theory of an ERP system is consistent and as we define it in Lean, they all use "Standard Work and a Standard Language". Once the student is familiar with the standard work and language they can navigate any system that is used in the field. Thus having a system in the classroom is a big plus over those students who just utilize a textbook to learn about ERP systems. Last, textbooks have a very short shelf life, whereas an ERP system can be updated on the fly and available on demand.

Another advantage of utilizing an ERP system in the classroom is that the student now will learn and appreciate how a MRP II system, Customer Requirements Management-CRM System, Purchasing, Estimating, Marketing and Sales, Manufacturing, Human Resources, DRP, Logistics and Transportation systems need to be synchronized so that the Business Plan can be met. This is truly in the context of Operations Management and ultimately Supply Chain Management. The ultimate winner is the customer and supplier both internal and external ones.

As an end result, students who have this skill set can now enter the workforce with "Same Day Skills" whereas they do not have to go through remedial training once they are hired and on the job. This is critical since time is money in the scheme of things. Companies who hire these individuals want to have employees who can navigate ERP systems with the least amount of training and can find solutions to problems that are associated in meeting the business plan and issues that occur within the internal and external supply chain that the organization operates in. In the end, this separates out the Best in Class from the Laggards. Only those who can maintain a global system will be able to navigate the challenges that they will have to deal with in the future.

\section{Major Ideas}

From the late 1970s through the mid nineties to today, J. O’Sullivan, D. Goldensohn and R. Hinton worked for various manufacturing firms including IBM, Universal Instrument, Grumman, Eaton, Raytheon, and Arkwin Industries to name a few. Through this time electronic systems devoted to materials management were in their infancy. Unlike modern Enterprise Resource Planning (ERP) systems, the components of these systems didn't easily communicate with each other. One had to either have a good understanding of both computer systems and inventory systems or have access to a programmer with those skill sets.

ERP has its roots in MRP and in improving quality. This isn't a new concept as historically craftsman organized themselves into guilds in order to preserve and promote quality among guild members. These concepts helped foment the Industrial Revolution of the early 1800s by focusing on product inspection. Throughout the 
$20^{\text {th }}$ century quality processes were developed and infused throughout the manufacturing process rather than "catching mistakes" at the end and became known as total quality management (TQM). More recently use of this term has decreased but the practices continue to be followed. "New quality systems have evolved from the foundations of Deming, Juran and the early Japanese practitioners of quality, and quality has moved beyond manufacturing into service, healthcare, education and government sectors” (History of Quality, n.d.).

ERP also has roots in materials management practices developed in the 1960s, when computers were beginning to be used to support business functions in industry, through 1980s, when they were firmly established. Initial systems focused on managing the procurement, maintenance, and disbursement of inventory. As computing power and capabilities improved, so did the capabilities of these inventory management systems. The first reproduced the manual reorder point (ROP) systems for manufacturing planning and control (MPC) currently in practice. In the 1970s, materials requirements planning (MRP) systems integrated manufacturing, planning, and procurement processes. This made manufacturers more "market-friendly" establishing MRP as a primary mechanism for planning parts and materials. In the 1980s as more manufacturing and business processes were being incorporated into newer, more complex systems which were referred to as manufacturing resource planning (MRP II) to differentiate them from their main component, MRP. The main shortcoming of MRP II was that modules for any particular process rarely interacted with those controlling other processes. In addition, computer limitations made it almost impossible to work in "real time". The first ERP systems were introduced in the 1990s. These attempted to address MRP II's shortcomings through tighter module integration and again due to technology improvements, permitting "real time” updates of all affected modules across the enterprise (Jacobs \& Weston Jr, 2007).

Fast forward to the present, improvements in computer technology have enabled these new systems to be developed. The processing power of large-scale systems allows what used to be separate systems to be integrated globally. However, technology without education is an "expensive paperweight”!

\section{Push Technology into Education}

Farmingdale State College has been using the Infor Visual ERP tool in the classroom since 2008 and has been extremely successful in preparing students for industry use. Dr. O’Sullivan has written many papers, presented at many conferences, written articles, journals and two textbooks with industry partner Gene Caiola of Synergy Resources for classroom use of this Visual ERP tool. The collaboration of this partnership is the reason why this is so successful. With subject matter experts providing insight into class preparation for faculty to create instruction for student readiness in the workforce has proven successful repeatedly in the Farmingdale ERP students now in industry [3]. This is the best way to bridge the gap and get very close to what is expected in companies ERP requirements for new employees. The Farmingdale State ERP Alliance has been established to promote successful industry collaboration. There are more than 3000 manufacturers in this territory with many requiring ERP skills for new employees. With the assistance of industry and associations that support manufacturing like the APICS NYC/LI chapter we can be better prepare and provide what is needed.

Collaborating across our two SUNY campuses to prepare students for the manufacturing and service opportunities is our objective. Farmingdale State College and Binghamton Universities efforts will allow for collaborative learning for manufacturing and job preparation across the State which is a focus for SUNY.

\section{Important to Binghamton}

Through the mid-1990s, the Southern Tier of New York State was largely supported by manufacturing. Today, while not the biggest employer, Manufacturing still accounts for 12\%, or 12,700 jobs in the Binghamton area. It is also the fourth largest employer. In a slowly growing economy, manufacturers need to be more efficient. Investing in technology and the education to exploit it may be a way to strengthen and possibly expand the manufacturing base locally. While many of these are small manufacturers, the area also supports Department of Defense (DoD) contractors such as BAE Systems and Lockheed Martin; companies which have already implemented ERP systems.

Binghamton's ERP course in the summer 2013 was supplemented by Blackboard. This allowed Prof. R. Hinton to provide additional materials both directly and indirectly related to ERP. These were available any time a student logged into the course site. It also provided tools for collaboration. Many of these (or some variation of them) are used in many organizations today. It is important that students not only know how to use them, but 
which one to use. Assignments do require them to use particular tools and given an explanation why it should be used. Students weren't only expected to be able to use software. It was important for them to understand the reasons behind implementing ERP; what could go wrong; what has gone wrong; and maybe most importantly, when to automate. In this first course there were obstacles as in any first attempt but they are being worked out in the process of continuous improvement of offering this ERP preparation to these students. Since the software was a major component of the course, arrangements were made to hold the class in a lab. This would allow for both discussion and directed instruction. It is also important to teach by example. Integration is a fundamental principle associated with ERP. Having lecture in a laboratory allows for flexibility to adjust class activities as the situation arises. It also allows for outside research performed by the students which is actually a very important element of the course. Rather than spending a lot of time lecturing, students are assigned research questions. They are given a venue to post that research which is then discussed as a group. This engages them more and they feel a sense of ownership of the material. Anything they didn't include in their post is provided during the discussion phase.

Currently the class size is small enough that the course has been scheduled in a design lab. This is a multimedia classroom with monitors on several walls. Computer stations are grouped by four and set up to face each other. Students can work both individually or in teams depending on the assignment.

The rationale was the benefits of students using this Real World Tool and being better prepared to serve in the workforce. Plans for more in depth collaborating amongst our colleges is underway in order to creatively design, instruct and teach using this Visual tool.

\section{Student Faculty Interaction}

Faculty members taking an interest in their student's academic progress could potentially make a significant contribution in increasing their intellectual and professional development [4].

Faculty-student interactions could take on a more intense flavor in a tutorial-style classroom, or in a hands-on style ERP class as experienced by this researcher. Such close, intense, interactions seem to enhance student learning and intellectual stimulation, with both student and faculty valuing the opportunity to know each other at an informal and personal level [4].

This apprentice type training, tutorial style class setting mirrors what very few companies do today in the US compared to years ago and what occurs in other areas of the world. The idea is for employees that are new to ERP when learning ERP to be in an apprenticeship type training situation. This allows for a supervisor to sit with the individual for close training relevant to their current and future ERP use or responsibilities.

\section{Conclusions}

Cross collaboration from SUNY Farmingdale and Binghamton for curriculum enrichment, development and student preparedness is our cumulative goal. As researchers, professionals, practitioners and decision-makers from the Academic, Private and Public Sectors, we have shared our findings, experience and knowledge in regards to the applications and impact of the use of ERP information and communication with this technology tool with hopes that it will entice others.

The demand pull of qualified ERP employees is absolute and the technology push of ERP systems in the classroom that are affordable and user friendly will improve our collaborations.

The continuous improvement of these relationship, techniques and skills will net a solution for the current state. The necessary alignment between industry and academia will allow for meeting the needs of industry.

The widespread implementation of ERP systems has increased the demand for professionals with knowledge of ERP systems and their underlying integrated processes. Business as well as government organizations are investing significantly in ERP systems with the goal of streamlining their business operations and reducing information fragmentation [5].

\section{References}

[1] O’Sullivan, J.A. (2014) Validating Academic Training versus Organizational Training Using ERP. Lambert Academic Publishing, Saarbrücken.

[2] O'Sullivan, J.A. (2011) Validating Academic Training versus Organizational Training: An Analysis in the Enterprise Resource Planning (ERP) Field. Dissertation, ACM, Pace University, New York. 
[3] Antonucci, L. and zur Muehlen, M. (2009) Developing an International Business to Business Process Curriculum: Extending the Classroom Walls with ERP Software.

[4] O’Sullivan, J.A. and Caiola, G. (2008) Enterprise Resource Planning a Transitional Approach from the Classroom to the Business World. McGraw Hill, New York.

[5] Cronan, T.P., Douglas, D.E., Alnuaimi, O. and Schmidt, P.J. (2009) 2009 ITRI, Working Paper Series, 122-1008, 1231008. 
Scientific Research Publishing (SCIRP) is one of the largest Open Access journal publishers. It is currently publishing more than 200 open access, online, peer-reviewed journals covering a wide range of academic disciplines. SCIRP serves the worldwide academic communities and contributes to the progress and application of science with its publication.

Other selected journals from SCIRP are listed as below. Submit your manuscript to us via either submit@scirp.org or Online Submission Portal.
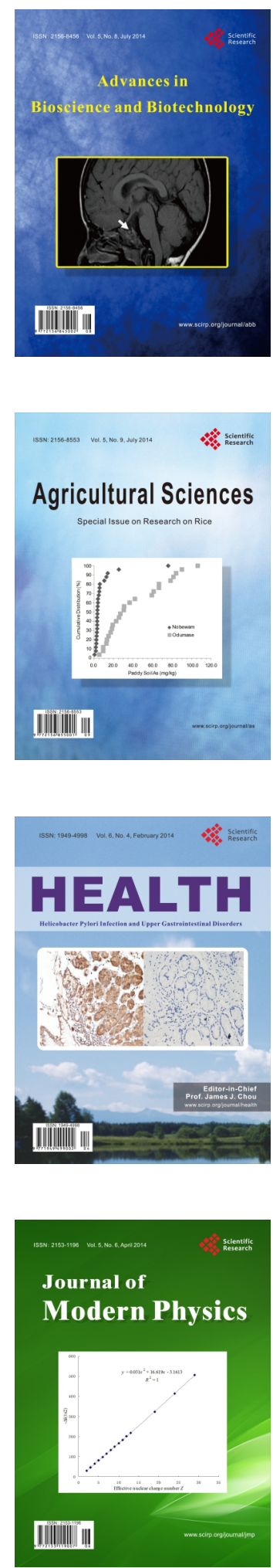
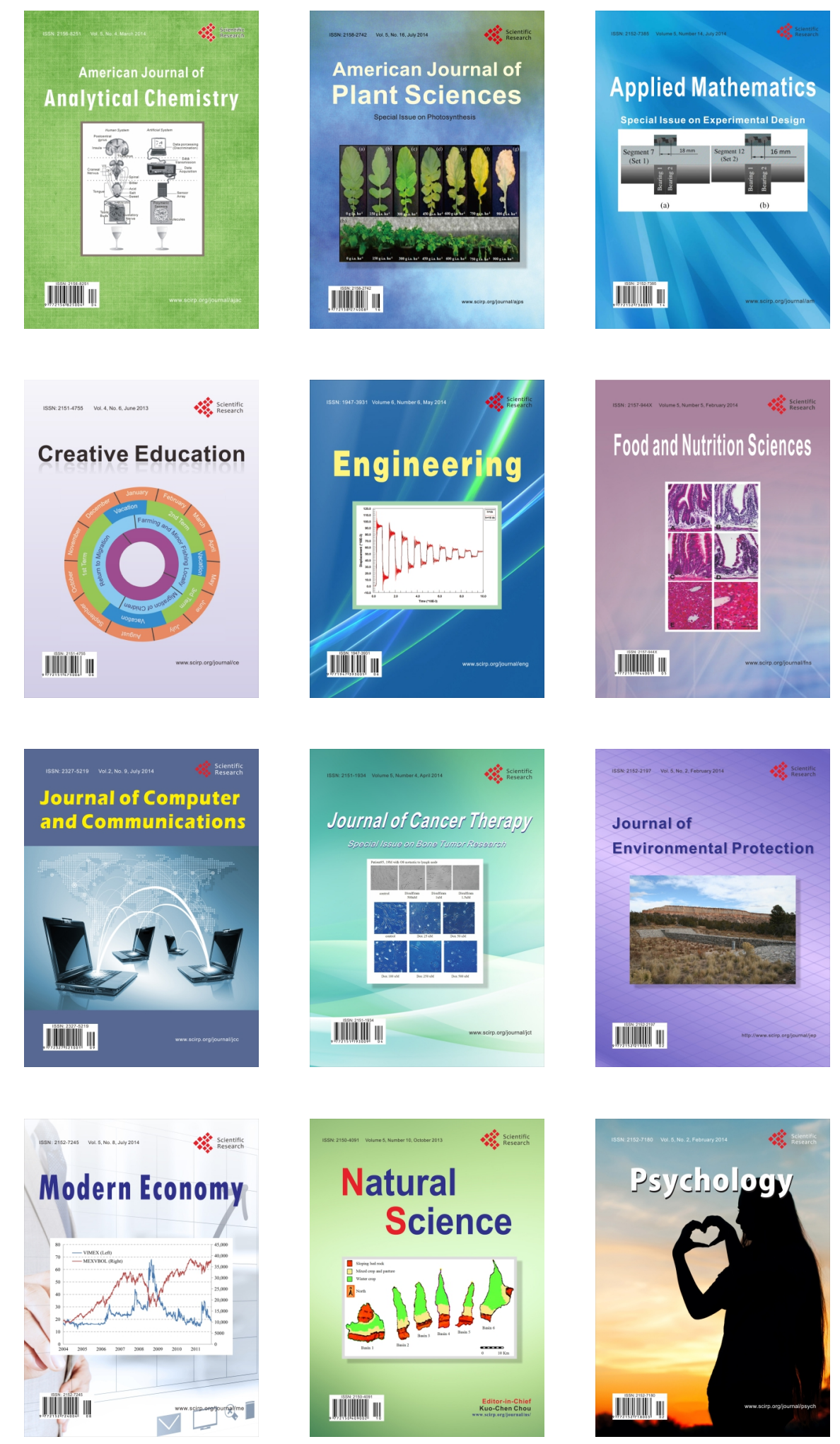